\title{
Study on Uterine Artery Doppler: Screening Tests in Hypertesive Disorders Of Pregnancy
}

\author{
G.Soumini
}

Dept of Obstetrics \& Gynaecology, Rangaraya Medical College Kakinada, India

\begin{abstract}
Objectives: To Study and analyse uterine artery Doppler Resistance index as predictor of Hypertensive disorders in pregnancy at 18 to 22 weeks

Materials and Methods: A Longitudinal Prospective observational Study was done on 274 antenatal mothers attending the outpatient department of Obstetrics \& Gynaecology, Rangaraya Medical College, Kakinada from January 2015 to October 2016 in 18 -35 yrs.Uterine artery Doppler resistance index ( 0.58 taken as cut-off) was recorded at $18-22$ weeks of gestation. Appropriate statistical tests were performed using SPSS software version 17. Sensitivity, specificity, positive and negative predictive value of the tests was calculated were followed up till term for development of pre-eclampsia

Results: The incidence of hypertensive disorders detected in positive Doppler screening was $16.2 \%(\mathrm{n}=44)$ where as $83.8 \%(\mathrm{n}=230)$ of the study subjects were not hypertensive. Majority of the cases $(67 \%)$ were found to have Mild preeclampsia $(n=29)$ followed by severe preeclampsia in $17 \%$ of cases $(n=7)$ and $8 \%$ of cases developed eclampsia and also $8 \%$ developed gestational hypertension $(n=4)$. 217 (79.2\%) of the study participants were found to be having RI $\leq 0.58$. Uterine artery Resistance Index as a predictor of hypertension has a sensitivity of $88.64 \%$ specificity of $92.17 \%$ positive predictive value of $68.42 \%$, negative predictive value of $97.7 \%$ and diagnostic accuracy was $91.6 \%$, this association is also found to be significant $[\mathrm{p}=0.000(<0.05)]$.
\end{abstract}

Conclusion: The present study concluded uterine artery resistance index as a better test in prediction of hypertension in pregnancy to prevent or reduce maternal as well as perinatal morbidity and mortality.

\section{Keywords: Pregnancy Induced Hypertension; Blood Pressure; Preeclampsia; Uterine Doppler}

\section{Introduction}

Hypertension in pregnancy remains an important cause of maternal and foetal morbidity and mortality ${ }^{1}$, with increased risk of adverse foetal, neonatal and maternal outcomes, including preterm birth, intrauterine growth restriction (IUGR), perinatal death, acute renal ,hepatic failure, antepartum haemorrhage, postpartum haemorrhage and maternal death ${ }^{2}$.

Worldwide about 76,000 pregnant women die each year from preeclampsia and related hypertensive disorders. And, the number of babies who die from these disorders is thought to be on the order of 500,000 per annum ${ }^{3}$.

India is estimated to account for over one third of all maternal deaths worldwide in 2015, with an approximate 58000 maternal deaths (19\%) and 45000 maternal deaths (15\%), respectively ${ }^{4}$.

Preeclampsia is diagnosed when $\mathrm{SBP} \geq 140 \mathrm{~mm} \mathrm{Hg}$ or DBP $\geq 90 \mathrm{~mm} \mathrm{Hg}$ on two occasions at least 6 hours apart, associated with proteinuria greater than $300 \mathrm{mg}$ per 24 hours or greater than $1 \mathrm{gm} / \mathrm{lit}$ in a random sample or protein $(\mathrm{mg} / \mathrm{dL}) /$ Creatinine ratio $(\mathrm{mg} / \mathrm{dL}) \geq 0.3$, dipstick reading of $1+$ after 20 weeks of gestation ${ }^{7}$. (ACOG 2013)
Early screening for preeclampsia may allow vigilant antenatal surveillance and appropriate timing of foetal delivery in order to avoid serious sequelae. Various haemodynamic and biochemical measures have been found to have limited accuracy as a screening measures for this condition ${ }^{5,6}$.

Preeclampsia is characterised by an imbalance between prostacycline and thrombaxane A2 production ${ }^{7}$, as well as failure of the second wave trophoblastic invasion of the endometrio-myometrial vasculature. The result is abnormal uteroplacental blood flow and this lead an idea of using Doppler assessment of uterine artery velocimetry waveforms as the method of screening for this antenatal complication $^{8}$.

Doppler is a non-invasive method for evaluation of fetoplacental circulation without any disturbance to human pregnancy ${ }^{9}$. A high Resistance Index, Pulsatility Index and persistent uterine artery notching in uterine artery Doppler wave form has shown as the best screening test ${ }^{10}$.

Severe Notching with an Abnormal Resistance Index: When the Resistance Index is abnormal (low-diastolic 


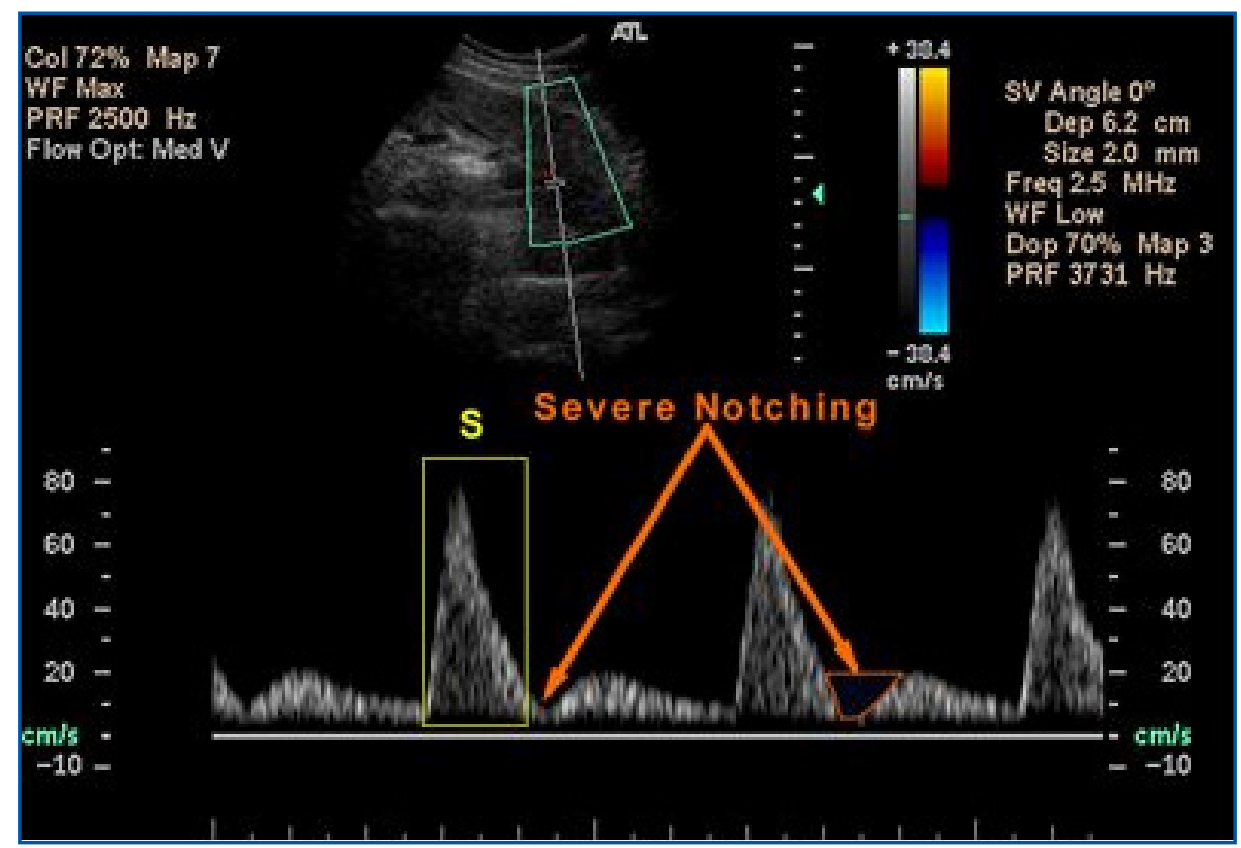

Fig. 1

flow) and a notch is present, this places the patient at the highest risk for adverse pregnancy outcome ${ }^{11}$.

Uterine artery doppler was considered abnormal between 18 and 23 weeks of gestation if

- $\quad$ Resistance index $>95^{\text {th }}$ centile.

- Early diastolic notch in either of the two uterine arteries.

- When the mean PI of both uterine arteries was > (1.45-.58).

Doppler is a non-invasive method for evaluation of fetoplacental circulation without any disturbance to human pregnancy. A high Resistance Index, Pulsatility Index and persistent uterine artery notching in uterine artery Doppler wave form has shown as the best screening test..

\section{Materials and Methods}

A Longitudinal Prospective observational Study was done on 274 antenatal mothers attending the outpatient department of Obstetrics \& Gynaecology, Rangaraya Medical College, Kakinada from January 2015 to October 2016 on $18-35$ yrs with singleton pregnancy who met inclusion criteria and non hypertensive.Uterine artery Doppler resistance index (0.58 taken as cut-off) was recorded at $18-22$ weeks of gestation. The subjects were followed up till term for development of pre-eclampsia

All women who meet the inclusion and exclusion criteria were taken into the study after signing an informed written consent. Detailed history was taken and thorough general physical examination was done and a Transabdominal Doppler ultrasonography for the measurement of Resistance Index at 18 to 22 weeks of gestation.

The results were documented. Subsequently they were followed up at 2 weekly intervals until term . At each visit blood pressure were recorded. The primary outcome is the development of pre-eclampsia or gestational hypertension.

Statistical Analysis: Appropriate statistical tests were performed using SPSS software version 17. Sensitivity, specificity, positive and negative predictive value of the tests was calculated.

\section{Result}

The incidence of hypertensive disorders was $16.2 \%(\mathrm{n}=$ 44) where as $83.8 \%(n=230)$ of the study subjects were not hypertensive(Fig 2)

\section{Distribution of Cases in to Various Groups}

Table1: Distribution of Cases in to various categories.

\begin{tabular}{|l|c|c|}
\hline $\begin{array}{l}\text { Categories of HTN } \\
\text { Disorders }\end{array}$ & $\begin{array}{c}\text { No of } \\
\text { cases }\end{array}$ & Percentage \\
\hline Gestational hypertension & 4 & $8 \%$ \\
\hline Mild Pre Eclampsia & 29 & $67 \%$ \\
\hline Severe Pre Eclampsia & 7 & $17 \%$ \\
\hline Eclampsia & 4 & $8 \%$ \\
\hline HELLP Syndrome & 0 & $0 \%$ \\
\hline Total & $\mathbf{4 4}$ & $\mathbf{1 0 0 \%}$ \\
\hline
\end{tabular}




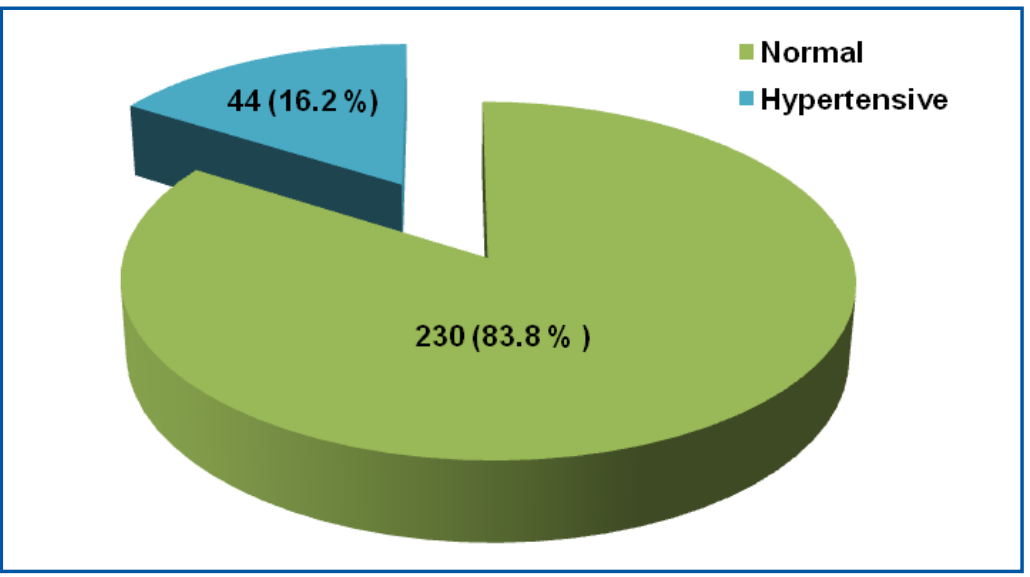

Fig. 2

Majority of the cases (67\%) were found to have Mild preeclampsia $(\mathrm{n}=29)$ followed by severe preeclampsia in $17 \%$ of cases $(n=7)$ and $8 \%$ of cases developed eclampsia and also $8 \%$ developed gestational hypertension $(\mathrm{n}=4)$. No cases were diagnosed with HELLP syndrome(Table 1).

Age Distribution: The incidence of hypertension in pregnancy was found to be more among $21-25$ years of age group (50\%) and normotensive subjects were more among $18-20$ years. There was a statistically significant difference in the incidence of hypertension $(\mathrm{p}<0.05)$ (table 4$)$ which was more among younger women compared to elderly.

Parity: When compared with parity between normotensive $\&$ hypertensive patients, majority of them were primigravida in both the groups $(67.7 \% \& 75 \%)$ but there is no significant difference statistically between the two groups $(\mathrm{p}>0.05)$

Body Mass Index: Majority of the study subjects were within the normal BMI range ,most of the hypertensive patients were also found to be having normal BMI (66.7\%) table 2, however when mean BMI of the two groups when compared has shown that hypertensive subjects had higher mean BMI and the difference was found to be statistically highly significant $(\mathrm{p}<0.01)$ (student $\mathrm{t}$ test). The mean BMI has a highly significant difference between the two groups .

Socioeconomic Status: Majority of patients belong to lower middle class in both the normotensive \& hypertensive group patients $(38.6 \% \& 48.3 \%)$. There is no significant difference between the two groups ( $p>0.05$ ) based on socioeconomic scale.

Onset of Hypertension: Onset of hypertension was higher among $28-34$ weeks of gestation. No cases of hypertension were seen among women with $20-24$ weeks of gestation in this study.

Uterine Artery Resistance Index: Out of 274 women, 57 cases were positive for Uterine Artery Resistance Index (21\%) 239 women were negative $(87.1 \%)$. The resistance index (RI) was positive (> 0.58) among 57 (20.8\%) as shown in table no.2, and $217(79.2 \%)$ of the study participants were found to be having $\mathrm{RI} \leq 0.58$.

This table 3 shows a highly significant difference $(\mathrm{p}<$ 0.01 ) in the incidence of hypertension among women, who were tested for Resistance Index. Similarly sensitivity; specificity, positive predictive value (PPV), negative predictive value (NPV) and diagnostic accuracy were also calculated.

As shown in the table 4 Resistance Index has a sensitivity of $88.64 \%$ (true positives) higher and lower specificity of $92.17 \%$ (true negatives).

\section{Discussion}

The incidence of hypertension in pregnancy was found to be $16.2 \%(n=44)$ according to this study, which closely

Table2: Comparison of Resistance Index at 18 - 20 weeks.

\begin{tabular}{|c|c|c|c|c|c|c|}
\hline Resistance Index & Developed HTN & $\%$ & Not developed HTN & $\%$ & No of cases & $\%$ \\
\hline$\leq 0.58$ & 5 & 2.3 & 212 & 97.7 & 217 & 100 \\
\hline$>0.58$ & 39 & 68.4 & 18 & 31.6 & 57 & 100 \\
\hline Total & $\mathbf{4 4}$ & $\mathbf{1 6 . 1}$ & $\mathbf{2 3 0}$ & $\mathbf{8 3 . 9}$ & $\mathbf{2 7 4}$ & $\mathbf{1 0 0}$ \\
\hline
\end{tabular}

Resistance index compared with normal and hypertensive women ${ }^{2}$ value -75.615 value -0.000 Efficacy of Resistance Index: 
Table3: Cross tabulation of RI with hypertension

\begin{tabular}{|c|c|c|c|}
\multirow{2}{*}{ Resistance Index } & \multicolumn{2}{|c|}{ Hypertension } & \multirow{2}{*}{ Total } \\
\cline { 2 - 4 } & Yes & $\mathrm{No}=18(\mathrm{FP})$ & $57(\mathrm{a}+\mathrm{b})$ \\
\hline Positive & $\mathrm{a}=39(\mathrm{TP})$ & $\mathrm{d}=212(\mathrm{TN})$ & $217(\mathrm{c}+\mathrm{d})$ \\
\hline Negative & $\mathrm{c}=5(\mathrm{FN})$ & $\mathbf{2 3 0}(\mathbf{b}+\mathbf{d})$ & $\mathbf{2 7 4}$ \\
\hline Total & $\mathbf{4 4}(\mathrm{a}+\mathrm{c})$ & \\
\hline
\end{tabular}

$\chi^{2}$ value $-146.396 p$ value -0.000

Table4: Evaluation of Resistance Index.

\begin{tabular}{|c|c|}
\hline Factor & $\%$ \\
\hline Sensitivity $\{a /(a+c) * 100\}$ & $88.64 \%$ \\
\hline Specificity $\{d /(b+d) * 100\}$ & $92.17 \%$ \\
\hline $\operatorname{PPV}\{a /(a+b) * 100\}$ & $68.42 \%$ \\
\hline $\operatorname{NPV}\{d /(c+d) * 100\}$ & $97.7 \%$ \\
\hline Diagnostic accuracy $\{(a+d) /(a+b+c+d) * 100\}$ & $91.6 \%$ \\
\hline
\end{tabular}

correlates with different studies done elsewhere. Uterine artery Resistance Index as a predictor of hypertension has a sensitivity of $88.64 \%$ specificity of $92.17 \%$ positive predictive value of $68.42 \%$, negative predictive value of $97.7 \%$ and diagnostic accuracy was $91.6 \%$, this association is also found to be significant $[\mathrm{p}=0.000(<$ $0.05)$ ] in our study.

The present study concluded uterine artery resistance index as a better test in prediction of hypertension in pregnancy According to national eclampsia registry the incidence of hypertensive disorders in India is found to be $10.8 \%$. (FOGSI Jan - feb 2014) $^{12}$ In a study done by Salako et al ${ }^{13}$ the incidence of hypertension was $15.1 \%$, However the overall prevalence of hypertensive disorders in pregnancy was $7.8 \%$ in a study done by Manjusha Sajith et al.On further distribution of cases into various categories, Mild preeclampsia was found to be the leading presentation occurring among $67 \%(\mathrm{n}=29)$ of the cases followed by severe preeclampsia in $17 \%(n=7)$ and Eclampsia in $8 \%(n$ $=4$ ) of the cases. $8 \%$ developed gestational hypertension ( $\mathrm{n}$ $=4$ ) and no cases were diagnosed with HELLP syndrome. In a study done by Manjusha Sajith et $a{ }^{14}$ Similar findings were noted with Preeclampsia as the most common cause of hypertension during pregnancy (71.2\%). Out of 44 cases who developed hypertension in this study, the time of onset of hypertension was most frequently found among $28-34$ weeks of gestation, i.e. $66.7 \%(n=29)$ followed by $25 \%(n$ $=11)$ during $24-28$ weeks and remaining $8.3 \%(\mathrm{n}=11)$ developed hypertension more than 34 weeks of gestation.

The resistance index $(\mathrm{RI})$ was positive $(>0.58)$ among 57 cases $(20.8 \%)$ ( table no.2), out of which 44 cases $(77.2 \%)$ developed hypertension and the remaining 13 cases $(22.8 \%)$ were normotensive. There is a highly significant difference $(p<0.01)$ in the incidence of hypertension among women, who were tested positive for uterine artery Resistance Index. North RA et al in their study on uterine artery Doppler flow velocity wave forms in the $2^{\text {nd }}$ trimester for the prediction of preeclampsia and fetal growth retardation identified $51 \%$ of women with abnormal uterine artery resistance index associated with increased risk of preeclampsia and $\mathrm{FGR}^{15}$. In a large prospective study done by Katie $\mathrm{M}$ Groom et al, the rate of adverse pregnancy outcome and preeclampsia was higher among the group with abnormal resistance index, Which differed among groups 1 (85 [4.6\%]), 2 (9 [7.6\%], 3 (7 [5.5\%]), and $4(15[18.3 \%])$ with group 4 having the highest $\mathrm{t}^{16}$.

Uterine artery Resistance Index as a predictor of hypertension has a sensitivity of $88.64 \%$ specificity of $92.17 \%$ positive predictive value of $68.42 \%$, negative predictive value of $97.7 \%$ and diagnostic accuracy was $91.6 \%$. Bhattacharyya S. K. et al in their study on the role of uterine artery doppler flow velocimetry in predication of preeclampsia observed a sensitivity of $73.3 \%$ and specificity of $86.48 \%$ in high risk group ${ }^{17}$. Coleman et al observed a sensitivity of $91 \%$, specificity of $42 \%$, positive predictive value of $37 \%$ and negative predictive value of $92 \%{ }^{18}$. Padmalatha V.V et al ${ }^{19}$ observed $60 \%$ sensitivity,92\% specificity, $16 \%$ positive predictive value, $99 \%$ negative predictive value.

\begin{tabular}{|l|c|c|c|c|} 
Study & $\begin{array}{c}\text { Sensitivity } \\
(\mathbf{\%})\end{array}$ & $\begin{array}{c}\text { Specificity } \\
(\%)\end{array}$ & $\begin{array}{c}\text { PPV } \\
(\%)\end{array}$ & $\begin{array}{c}\text { NPV } \\
(\%)\end{array}$ \\
\hline Present study & 88.64 & 92.17 & 68.42 & 97.7 \\
\hline $\begin{array}{l}\text { Bhattacharyya S. } \\
\text { K. et al }\end{array}$ & 73.33 & 86.48 & 68.74 & 88.88 \\
\hline Coleman et al $^{18}$ & 91 & 42 & 37 & 92 \\
\hline $\begin{array}{l}\text { Padmalatha vv } \\
\text { et al }\end{array}$ & 60 & 92 & 16 & 99 \\
\hline
\end{tabular}


The study showed a relatively higher specificity for Uterine artery resistance index with $92.17 \%$ respectively sensitivity of $83.64 \%$ for Uterine artery resistance index. CA Meads et $\mathrm{al}^{20}(2008)$ conducted systematic reviews of accuracy and effectiveness in methods of prediction and prevention of preeclampsia, for the 27 tests they reviewed some tests appeared to have high specificity, but at the expense of compromised sensitivity, the only Doppler test with a sensitivity of over $60 \%$ was resistance index. Kanwal Gujral et $\mathrm{al}^{21}$ (2016) in their review on prediction of preeclampsia concluded that Doppler is the primary screening modality for prediction of PE and individually, no biomarker has shown to have sufficient clinical value in prediction of PE. Various studies showed different diagnostic indices with a sensitivity of $63 \%$ (RI $>0.58)$ Steele (1990), 27\% (RI $>90^{\text {th }}$ percentile) North (1994) as reported in the study. The authors recommended a combination of uterine artery Doppler and maternal characteristics which offer a best predictive power. Bower et al. examined the uterine arteries in 2058 pregnancies at 18-22 weeks. An abnormal result, defined by a resistance index above the 95th centile or the presence of an early diastolic notch in either of the two uterine arteries, was found in $16 \%$ of the pregnancies. The sensitivity of the test was $75 \%$ for preeclampsia and $46 \%$ for intrauterine growth restriction, and the specificity was $86 \%$ for both. This study highlighted the fact that abnormal Doppler results provide a better prediction of the more severe types of pregnancy complications $^{22}$

\section{Conclusion}

Uterine artery Resistance Index as a predictor of hypertension has a sensitivity of $88.64 \%$ specificity of $92.17 \%$ positive predictive value of $68.42 \%$, negative predictive value of $97.7 \%$ and diagnostic accuracy was $91.6 \%$, this association is also found to be significant [p $=0.000(<0.05)]$. The present study concluded uterine artery resistance index as a better test in prediction of hypertension in pregnancy to prevent or reduce maternal as well as perinatal morbidity and mortality.

\section{Acknowledgements}

I would like to thank Dr.Sasikala HOD Obstetrics \&Gynaecology,Dr.Radha Prof RadioDiagnosis Dr.Harini JR, D.Anvitha for their support and analytical help

\section{Reference}

1. WHO recommendations for Prevention and treatment of pre-eclampsia. whqlibdoc.who.int/ publications/2011/9789241548335_eng.pdf

2. Manjusha Sajith, Vandana Nimbargi, Amit Modi, Ronak Sumariya, Atmaram Pawar. Incidence of pregnancy induced hypertension and prescription pattern of antihypertensive drugs in pregnancy. International journal of pharma sciences and research (ijpsr) vol 5 no 04 apr 2014.

3. Kuklina EV, et al. Hypertensive Disorders and Severe Obstetric Morbidity in the United States. Obstet Gynecol 2009; 113:1299-306.

4. Trends in Maternal Mortality: 1990 to 2015 Estimates by WHO, UNICEF, UNFPA, World Bank Group and the United Nations Population Division

5. Ekholm E. Hemodynamic measures in prediction of preeclampsia. Acta Obstet Gynecol Scand 1997; 76: 101-103.

6. Grunewald C. Biochemical prediction of pre-eclampsia.. Acta Obstet Gynecol Scand 1997 (Suppl 164);76:104- 107.

7. Walsh SW. Pre-eclampsia: an imbalance in placental prostacycline and thromboxane production. Am J Obstet Gynecol 1985;152:335-340

8. Gupta Shashi, Gupta Pradeep Kumar, Bodani Preeti ,Khamsera Anshu.Transvaginal doppler of uteroplacental circulation in early prediction of pre-eclampsia by observing bilateral uterine artery notch and resistance index at 12-16 weeks of gestation. J obset gynecol India 2009;59(6):541-546

9. Ventura SJ, Martin JA, Curtin SC, Mathews TJ, Park MM: Births: Final data for 1998. National Vital statistics reports: Hyattsville, MD. National center Health Statistics, 2000:48

10. Montan S.Sjoberg O-O. Svenningsen. N. Hypertension in pregnancy-fetal and infant outcome. Clin Exp Hypertens -Hyper in Pregnancy 1987; B62: 337-348

11. GreggoryR.Devore. Fetal diagnostic centres 1st trimester screening. http://www.fetal.com/NT\%20Screening/10\%20 Uterine \%20Artery\%20Meas.html

12. Eclampsia registry the incidence of hypertensive disorders in India Journal of obstetrics \& gynecology of India vol 64 Jan - Feb 2014.

13. Lim KH, Zhou Y, Janatpour M, McMaster M, Bass K, Chun SH, Fisher SJ: Human cytotrophoblast differentiation/ invasion is abnormal in pre-eclampsia. Am J Pathol 151: 1809-1818, 1997

14. Bakht R., Nikkhoo N., Aghababaei S. Assessing rollover test in early diagnosis of preeclampsia. The Journal of Qazvin University of Medical Sciences, Fall 2004 , Volume Number 32

15. Low JA. The current status of maternal and fetal blood flow velocimetry. Am J Obstet Gynecol 1991;164:1049.

16. Katie MG, Robyn A, North, Peter RS, Eliza H.Y.Chan, Rennae S. Taylor, Gustaaf A.Dekker.et,al. Patterns Of change in uterine artery doppler studies between 20 and 24 weeks of gestation and pregnancy outcome. The American college of obsteticians and Gynoecologist published 2009;113(2)332-338.

17. Maulik D, Doppler Ultrasound in Obstetrics and Gynecology 2nd Revised and Enlarged Edition

18. Bhattacharyya Sanjoy Kumar, Kundu Sarmila, Kabiraj Sankar . Prasad Prediction of Preeclampsia by Midtrimester Uterine Artery Doppler Velocimetry in High-Risk and Low- 
Risk Women. The Journal of Obstetrics and Gynecology of India (May-June 2012) 62(3):297-300

19. Padmalatha VV, Rao PSS, Susan Abraham, Asha Thomas. Predicting Pre-Eclampsia \& Fetal Growth Restriction through Second Trimester Uterine Artery Doppler Sonography: An Indian experience IOSR Journal of Dental and Medical Sciences (IOSR-JDMS) e-ISSN: 2279-0853, p-ISSN: 2279-0861.Volume 12, Issue 1 (Nov.- Dec. 2013), PP 21-26

20. CA Meads, JS Cnossen, S Meher, A Juarez-Garcia, G ter Riet, L Duley, TE Roberts, BW Mol, JA van der Post, MM
Leeflang, PM Barton, CJ Hyde, JK Gupta and KS Khan .Methods of prediction and prevention of pre-eclampsia: systematic reviews of accuracy and effectiveness literature with economic modeling. Health Technology Assessment 2008; Vol. 12: No. 6

21. Kanwal Gujral, Sakshi Nayar. Prediction of Pre-eclampsia. J. Fetal Med. (June 2016) 3:55-61

22. Bower S, Schuchter K, Campbell S. Doppler ultrasound screening as part of routine antenatal scanning: prediction of preeclampsia and intrauterine growth retardation. $\mathrm{Br} \mathrm{J}$ Obstet Gynaecol 1993;100:989-94.

*Corresponding author:

Dr. G.Soumini, Associate ProfessorObstetricsGynaecology, Rangaraya Medical College, KAKINADA

Email: doctorsoumini@yahoo.co.in 